\title{
Structural and Optical Properties of a Pd(II) Complex with 1-Nonyl-3,4-bis(methylthio)pyrrole
}

\author{
Jun-Gill Kang," Hyung-Kook Cho, Changmoon Park, Sung Kwon Kang, In Tae Kim,"* Sang Woo Lee, \\ Ha Hyeong Lee, ${ }^{\dagger}$ Young Nam Lee, ${ }^{\dagger}$ Sang Hee Cho, ${ }^{\dagger}$ Joo Hyoung Lee, and So Ha Lee ${ }^{\ddagger}$ \\ Department of Chemistry, Chungnam National Lnversity, Daejeon 305-76-, Korea. ${ }^{*}$ E-mail; jgkangach ack \\ -Department of Chemistry Kwangwoon Linwersity, Seoul 139-701, Korea. "E-mail: itkimakn'ackr \\ -Life Sciences Division, Korea Institute of Science and Technologv, P.O. Box 131, Cheongryang, Seoul 130-650, Korea \\ Received July 11, 2007
}

Key Words : Palladium(II). 1-Nonyl-3.4-bis(methylthio)py rrole. Crystal structure. Luminescence. Quantum mechanical calculation

Over the past two decades. aromatic heterocyclic rings such as thiophene and pyrrole have attracted great interest due to the possible applications of the corresponding polymers. Highly conjugated conducting polymers are excellent materials for electronic devices. for example. electrolytic capacitors. actuators. sensors. artificial muscles, and lightemitting diodes. ${ }^{1}$ An interesting feature of the pyrrole system is the ability to prepare many functionalized polymers by polymerizing pyrrole derivatives monomers. An electrochemically prepared polypyrrole shows high conductivity, relative stability to air and moisture in its oxidized form. the ability to form strong coherent films. and ease of synthesis. ${ }^{2}$ The properties of polypyrrole have also been modified by polymerizing pyrrole derivatives with 3-methyl. 3.4-dimethy' substituents. The conductivities of these polymers are 4 and $10 \mathrm{Scm}^{-1}$. respectively. ${ }^{3}$ Previously. we reported the synthesis and properties of substituted polypyrrole derivatives such as poly(1-hexyl-2.5-pyrrolylene) $\left(1.2 \times 10^{-6} \mathrm{Scm}^{-1}\right)$ and poly (1-hexyl-2.5-pytrolylene vinylene) $\left(2.5 \mathrm{Scm}^{-1}\right)$. The striking difference in the conductivity' between them could be due to steric interactions between adjacent rings. ${ }^{4} \mathrm{~A}$ new soluble conducting polymer. poly'(1hexyl-3,4-dimethyl-2.5-pyrrolylene), shows strong blue luminescence with a quantum yield of $\mathrm{Q}=36 \% .{ }^{5}$ Based on the results of calculations. it appears that the enhanced quantum yield of the polymer results mostly from conjugation between neighboring pyrrole rings. Goldoni et al ${ }^{5}$ reported the synthesis and properties of new conjugated compounds with alkylthio since thioether ligands are wellknown for their ability to complex soft transition metal ions. Such conjugated compounds could act as probes or modulators of the activity of the catalytic centre. In this paper. we describe the synthesis. and structural and optical properties of a new [ $\mathrm{PdCl}_{\{}\{1-$ nonyl-3,4-bis(methylthio)pyrrole\}] (3) made by exchanging the benzonitrile ligands in $\left[\mathrm{PdCl}_{\mathbf{y}^{-}}\right.$ $\left.(\mathrm{PhCN})_{2}\right]$ for pyyrrole derivatives with thioether side chains. The new palladium(II) complex (3) will form a new conjugated conducting polymer using oxidative polymerization.

The single-cry'stal X-ray structure of the Pd(II) complex was determined at room temperature. A view of the molecule is shown in Figure 1. The crystal contains a discrete mononuclear unit of the complex. in which Pd forms a four-

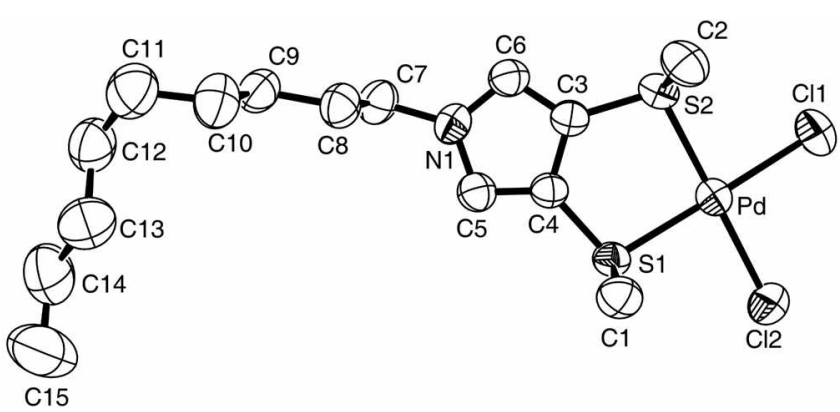

Figure 1. Perspective ORTEP drawing of the complex, showing the atom-numbering. Thermal ellipsoids of $50 \%$ are shown.

coordinated complex with two $\mathrm{Cl}$ and two $\mathrm{S}$ atoms. As listed in Table 1. the Pd-S distances are 2.2795(9) and 2.2763(10) A. which are very comparable with those observed in other Pd complexes with aryl alkyl $(2.259(2), 2.266(2) \mathrm{A}){ }^{7}$ dithioether $(2.316(2)$ and $2.297(2) A){ }^{8}$ pyrrolthiosemicabazone (2.241(4) and $2.244(4) A)^{9}$ or dibenzyll sulfide $(2.258(2)$ and $2.277(2)$ A) ligand ${ }^{(l)}$ The Pd-Cl distances of $2.3051(10)$ and $2.3099(10) \AA$ are slightly longer than those of Pd-S. The sum of angles about $\mathrm{Pd}\left(\mathrm{Cl1}-\mathrm{Pd}-\mathrm{Cl} 2\right.$ 93.93(4) ${ }^{\circ}$. Cl2-Pd-S1 $87.21(4)^{\circ}$. S1-Pd-S2 $86.59(4)^{\circ}$. S2-Pd-Cl1 $\left.86.59(4)^{\circ}\right)$ is $360.00^{\circ}$. The rms deviation of the five atoms from the leastsquare's plane is only $0.0003 \mathrm{~A}$. These results indicate that the four-coordinated Pd unit is exactly square planar. The coordination of $\mathrm{Pd}$ to two $\mathrm{S}$ atoms results in a five-member ring between $\mathrm{Pd}$ and the pyrrole ring. The bond lengths of S1-C4 and S2-C3 are 1.756(3) and 1.753(4) A. respectively:

Table 1. Selected bond lengths $(\AA)$ and angles $\left({ }^{\circ}\right)$ for $\left[\mathrm{PdCl}_{2}\{1-\right.$ nony-3,4-bis(methylthio)pyrrole; ]

\begin{tabular}{llll}
\hline $\mathrm{Pd}-\mathrm{S}(1)$ & $2.2795(9)$ & $\mathrm{Pd}-\mathrm{S}(2)$ & $2.2763(10)$ \\
$\mathrm{Pd}-\mathrm{Cl}(1)$ & $2.3051(10)$ & $\mathrm{Pd}-\mathrm{Cl}(2)$ & $2.3051(10)$ \\
$\mathrm{S}(1)-\mathrm{C}(1)$ & $1.816(3)$ & $\mathrm{S}(1)-\mathrm{C}(4)$ & $1.756(3)$ \\
$\mathrm{C}(3)-\mathrm{S}(2)$ & $1.753(4)$ & $\mathrm{S}(2)-\mathrm{C}(2)$ & $1.812(4)$ \\
$\mathrm{N}(1)-\mathrm{C}(7)$ & $1.470(4)$ & $\mathrm{C}(5)-\mathrm{N}(1)$ & $1.362(4)$ \\
$\mathrm{N}(1)-\mathrm{C}(6)$ & $1.363(4)$ & & \\
$\mathrm{S}(2)-\mathrm{Pd}-\mathrm{S}(1)$ & $92.27(3)$ & $\mathrm{S}(2)-\mathrm{Pd}-\mathrm{Cl}(1)$ & $86.59(4)$ \\
$\mathrm{S}(1)-\mathrm{Pd}-\mathrm{Cl}(2)$ & $87.21(4)$ & $\mathrm{Cl}(1)-\mathrm{Pd}-\mathrm{Cl}(2)$ & $93.93(4)$ \\
$\mathrm{C}(3)-\mathrm{S}(2)-\mathrm{Pd}$ & $101.4(12)$ & $\mathrm{C}(5)-\mathrm{N}(1)-\mathrm{C}(6)$ & $110.0(3)$ \\
$\mathrm{C}(5)-\mathrm{N}(1)-\mathrm{C}(7)$ & $125.4(3)$ & $\mathrm{C}(6)-\mathrm{N}(1)-\mathrm{C}(7)$ & $124.6(3)$ \\
\hline
\end{tabular}




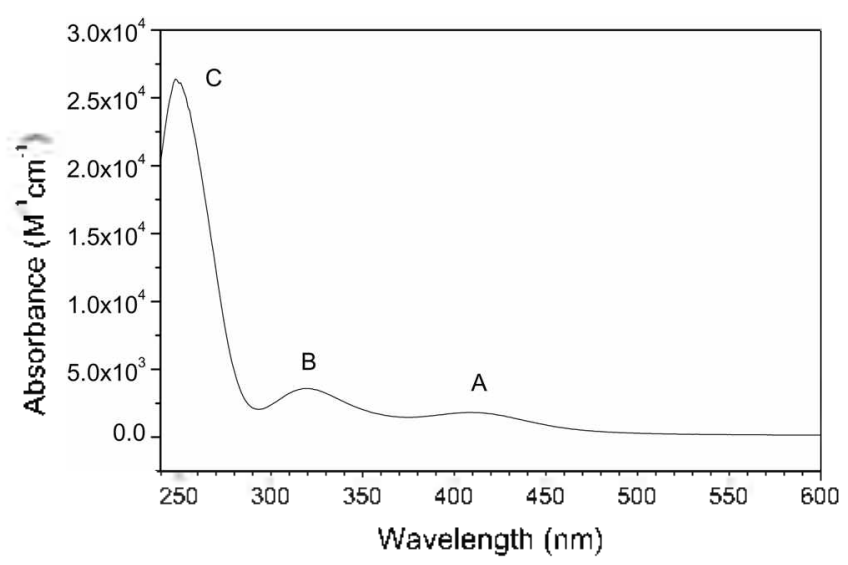

Figure 2. Absorption spectrun of (3) dissolved in $\mathrm{CH}_{2} \mathrm{Cl}_{2}$.

These values are in agreement with those for Pd-S complexes. ${ }^{(2,11)}$ In the five-mentber ring of the Pd coordination environment. the sum of five angles (S1-Pd-S+ 92.27(3)". Pd-S4-C3 101.40(12) ${ }^{\circ}$. S4-C3-C2 122.6(3) , C3-C2-S1 $\left.121.9(3)^{\circ}, \mathrm{C} 2-\mathrm{SI}-\mathrm{Pd} 103.86(13)^{\circ}\right)$ is $542.03^{\circ}$ and the rns deviation of the five atoms from the least-square's plane is $0.0320 \mathrm{~A}$. indicating that the five-member ring is almost square planar.

Figure 2 shows the absorption spectrum of the $\mathrm{Pd}(\mathrm{II})$ complex dissolved in $\mathrm{CH}_{2} \mathrm{Cl}_{2}$. The $\mathrm{Pd}(\mathrm{II})$ complex produced two weak absorption bands at $409 \mathrm{~nm}\left(\varepsilon=1.8 \times 10^{3} \mathrm{M}^{-1}\right.$ $\left.\mathrm{cm}^{-1}\right)$ and $320 \mathrm{~nm}\left(\varepsilon=2.7 \times 10^{3} \mathrm{M}^{-1} \mathrm{~cm}^{-1}\right)$. respectively. and a strong band at $248 \mathrm{~lm}\left(\varepsilon=26.4 \times 10^{3} \mathrm{M}^{-1} \mathrm{~cm}^{-1}\right)$ (hereafter. these bands are referred to as A-, B- and C-absorption bands in order of increasing energy). The luminescence and excitation spectra of the free ligand and the $\mathrm{Pd}(\mathrm{II})$ complex were measured in $\mathrm{CH}_{2} \mathrm{Cl}_{2}$. As shown in Figure 3, although the Aand $\mathrm{B}$-band transitions of the free ligand were almost forbidden. the A- and B-band excitations produced the 525 and $390 \mathrm{rm}$ luminescence, respectively. The luminescence properties of these two bands are very similar to those of the thiol and pyrrole derivatives. ${ }^{11.13}$ respectively. For the $\mathrm{Pd}(\mathrm{II})$ complex. the B-and excitation also produced the $390 \mathrm{~mm}$ luminescence. but the A-band excitation yielded a new emission band peaking at $470 \mathrm{~nm}$. The $470 \mathrm{~nm}$ band of the $\mathrm{Pd}(\mathrm{II})$ complex could be associated with the charge transfer from the ligand to Pd(II).

In addition. the structural property of the complex molecule was studied using Gaussian 03 for quantum mechanical calculation. ${ }^{13}$ SDD basis functions (LanL2DZ for Pd; 6$3 \mathrm{lG}(\mathrm{d})$ for $\mathrm{S}$ and $\mathrm{Cl}$ : 6-31G for $\mathrm{H} . \mathrm{C}, \mathrm{N}$ and $\mathrm{O}$ ) were used to optimize the geometry, and the configuration interaction singles (CIS) calculations were applied to elucidate interpret the experimental absorption data. The optimized geometry is in good agreement with the observation. The calculated bond lengths of $\mathrm{Pd}-\mathrm{Cl}(2.3422 \mathrm{~A})$ and $\mathrm{Pd}-\mathrm{S}(2.4707 \mathrm{~A})$ are slightly longer than the corresponding observed lengths. The calculated bond angles (Cll-Pd-Cl2 95.89, $\mathrm{Cl} 2-\mathrm{Pd}-\mathrm{Sl}$ $87.64^{\circ}, \mathrm{Sl}-\mathrm{Pd}-\mathrm{S} 288.65^{\circ}$. S2-Pd-Cll $87.64^{\circ}$ ) are very close to the observations. We calculated the electronic structures and transitions for the optimized geometry of the molecule
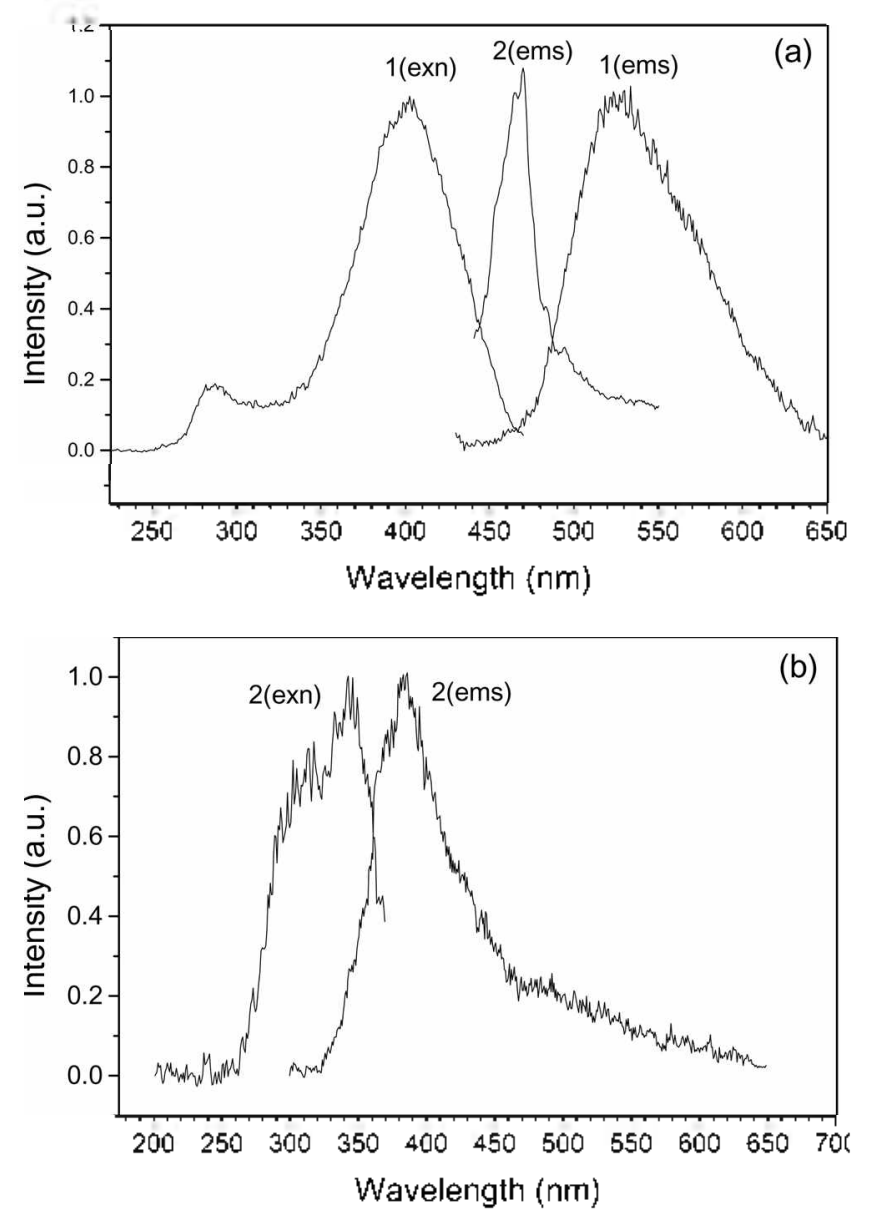

Figure 3. Emission and excitation spectra of the free ligand $(1)$ and the complex (2) dissolved in $\mathrm{CH}_{2} \mathrm{Cl}_{2}$ (concentration: $\mathrm{l} \times 10^{-1} \mathrm{M}$ ): (a) $\lambda_{\text {exr }}=409 \mathrm{~nm}$ and $\lambda_{\text {ens }}=525 \mathrm{~nm}$, and (b) $\lambda_{\text {exr }}=325 \mathrm{~nm}$ and $\lambda_{\text {ems }}=383 \mathrm{~nm}$.

using the ZINDO semiempirical method. ${ }^{13}$ The highest occupied molecular orbital (HOMO) consists of two $\pi$ bondings of pyrrole ring and the lowest unoccupied molecular orbital (LUMO) comprises $\sigma^{*}$-antibonding of Pd-S. The contribution of the Pd atomic orbitals to the LUMO is the greatest at $c a .50 \%$. The first excited state arises predominantly from the transition from $\sigma(\mathrm{Pd}-\mathrm{S})$ to the LUMO, while the oscillator strength of this transition with $f=0.003$ is almost negligible and the change of charge of $S$ atoms is negligible. Accordingly, the weak low-energy luminescence $\left(\hat{\lambda}_{\text {emms }}=470 \mathrm{~nm}\right)$ of the Pd(II) complex can be attributed to the intraligand transition of $S$ atoms.

Although the electronic structure and transitions of squareplanar complexes of platinum(II) and palladium(II) with $\mathrm{d}^{8}$ electronic configuration have been extensively investigated for various ligand systems. the luminescence properties of planar mononuclear Pd(II) and Pt(II) complexes have been not well understood. In this study, we reported the structural and optical properties of a new $\left[\mathrm{PdCl}_{2}\{1-n o n y l-3.4-b i s-\right.$ (methylthio)pyrrole\}]. The four-coordinated $\mathrm{Pd}$ unit and the five-member ring between $\mathrm{Pd}$ and the pyrrole ring form the square-planar geometry. The complex, excited by UV light. produced the violet and blue luminescence. The high-energy 


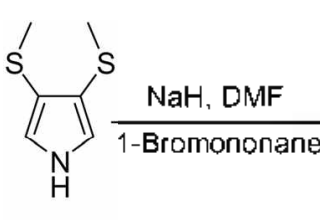

(1)
(2)

Scheme 1

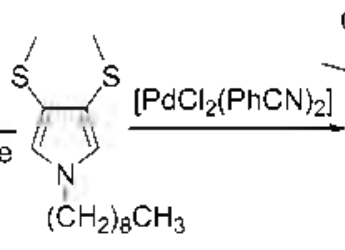

luminescence corresponds to the intraligand transition associated with the nitrogen atom. and the blue luminescence can be attributed to the intraligand transition of the sulfur atomis. In conjunction with the Pd(II) complex. the structural and luminescence properties of the Pt(II) complex are under investigation. These studies will propose the contprehensive model for the luminescence properties of square-planar complexes of $\mathrm{Pd}(\mathrm{II})$ and $\mathrm{Pt}(\mathrm{II})$

\section{Experimental Section}

1-Nonyl-3,4-bis(methylthio)pyrrole (2) was synthesized by alkylation of 3.4-bis(nethylthio)pyrrole with sodium hydride and l-bromononane. The chelate Pd complex 3 was obtained by reacting an equinolar amount of the dithioether compound (2) in dichloromethane with $\left[\mathrm{PdCl}(\mathrm{PhCN})_{2}\right]$. as shown in Scheme 1.

Synthesis of 1-nonyl-3.4-bis(methylthio)pyrole (2): Compound 3,4-bis(methylthio)pyrrole $(0.89$ g. 0.005588 mol) was dissolved in anlydrous dimethy lformamide (DMF: $8 \mathrm{~mL}$ ) and degassed before hexane-washed sodium hydride $(0.67 \mathrm{~g}, 0.0279 \mathrm{~mol})$ was added in one portion. The mixture was stirred for $15 \mathrm{~min}$ at room temperature. causing the initially yellow solution to become orange, whereupon 1 bromononane $(3.72 \mathrm{~mL}$. $0.0196 \mathrm{~mol})$ was added in one portion. causing a color change to yellow. The reaction mixture was stirred for $1 \mathrm{~h}$ at room temperature. and then water was carefully added. The yellow suspension was extracted with $\mathrm{CHCl}_{3}$. After drying $\left(\mathrm{MgSO}_{4}\right)$ and evaporating the solvent. the resulting yellow oil was purified by column chromatography on silica gel (ethyl Acetate:hexane = 1:4) to afford $1.52 \mathrm{~g}(95.6 \%)$ of the title compound as a yellow liquid: FTIR (neat) $3113(=\mathrm{C}-\mathrm{H}) .2956\left(-\mathrm{SCH}_{3}\right) .2921$ (-CH). $2854,1504(\mathrm{C}=\mathrm{C}) .1461,1336.1297,1121.972 .792$. $620 \mathrm{~cm}^{-1}$ : ${ }^{1} \mathrm{H}$ NMR $\left(400 \mathrm{MHz} . \mathrm{CDCl}_{j}\right) \delta 6.67(\mathrm{~s}, 2 \mathrm{H}), 3.78-$ 3.75 (t. $2 \mathrm{H}), 2.35$ (s, 6H). $1.72(\mathrm{~m}, 2 \mathrm{H}), 1.25$ (m. 12H). $0.87 \cdot$ 0.85 (t. $3 \mathrm{H}):{ }^{13} \mathrm{C}$ NMR $\left(100 \mathrm{MHz}, \mathrm{CDCl}_{3}\right) \delta 123.7 .117 .1$. $50.1,31.7 .31 .0,29.3 .29 .1,29.0 .26 .5,22.5 .20 .1,14.0$.

Synthesis of [ $\mathrm{PdCl}_{-\{1-n o n y l-3.4-b i s(m e t h y l t h i o) p y r r o l e\}]}$ (3): The 1-nonyl-3,4-bis(methylthio)pyrrole $(0.58 \mathrm{~g}$. $0.00203 \mathrm{~mol})$ was added to a solution of $\left[\mathrm{PdCl}_{2}\left(\mathrm{PhCN}_{2}\right]\right.$ $(0.78 \mathrm{~g} .0 .00203 \mathrm{~mol})$ in $\mathrm{dry}$ dichloromethane $(40 \mathrm{~mL})$. After stirring at room temperature for $20 \mathrm{~min}$. the solvent was removed in vacwo and benzene was added to give a yellow precipitate of $(3)$. which was filtered off and dried in vacuo with a yield of $83 \%(0.78 \mathrm{~g})$. FT-IR (KBr) 3121 (=C-
H), $3019.2991\left(-\mathrm{SCH}_{3}\right), 2929(-\mathrm{C} \cdot \mathrm{H}), 2858,1508(\mathrm{C}=\mathrm{C})$, 1465. 1418. 1297, 1125, 976.804, 749.624 $\mathrm{cm}^{-1}$. ${ }^{1} \mathrm{H}$ NMR $\left(400 \mathrm{MHz}, \mathrm{CDCl}_{3}\right) \delta 6.89-6.84$ (d. $\left.2 \mathrm{H}\right), 3.94-3.88$ (q. $2 \mathrm{H}$ ), $2.91-2.85$ (d. $6 \mathrm{H}$ ). $1.81-1.79$ (m. $2 \mathrm{H}$ ), $1.30-1.26$ (n. $12 \mathrm{H}$ ), 0.89-0.86 (t. $3 \mathrm{H}) ;{ }^{13} \mathrm{C}$ NMR (100 MHz. $\left.\mathrm{CDCl}_{3}\right) \delta 122.0$. 121.3. 31.7.31.1, 31.9, 30.5. 29.3. 29.1. 28.9. 26.4, 22.6, 14.0. UV-Vis-NIR: neutral filns: $\lambda_{\text {max }}=315.6 \mathrm{lum}$ and $41 \mathrm{l} \mathrm{mm}$ : Anal. Calcd for $\mathrm{C}_{15} \mathrm{H}_{27} \mathrm{Cl}_{2} \mathrm{PdNS}_{2}$ : C. 38.93: H. 5.88: N, 3.03 : S. 13.86. Found: C, 38.1866; H, 5.1398; N. 3.7207; S, 13.8274.

Crystal data for $\mathrm{C}_{15} \mathrm{H}_{27} \mathrm{Cl}_{2} \mathrm{NPdS}_{2}(3): M=462.80, T=$ 295 (2) K. $\lambda=0.71073 \AA$, monoclinic. space group $P 2(1) / \mathrm{c}$. $a=7.7838(8) \AA, b=16.3784(13) \AA . c=15.5354(10) \AA . \beta=$ $90.136(8)^{\circ}, \mathrm{V}=1980.5(3) \AA^{3} . Z=4, D_{\text {cal }}=1.552 \mathrm{Mg} / \mathrm{m}^{2}$, $F(000)=944, R_{1}(\mathrm{I}>2 \sigma(\mathrm{I}))=0.0377, \mathrm{wR}_{2}($ all data $)=0.0842$.

Acknowledgements. This research was partly supported by a research grant of Kwangwoon University (2006) and by the MIC (Ministry of Information and Communication), Korea, under the ITRC (Information Technology Research Center) support program supervised by the IITA (Institute of Information Teclunology Assessment) (IITA-2006-C1090$0603-0018$ ). This research was conducted in 2006 during the sabbatical research year of Kwangwoon University. JGK. $\mathrm{HKC}$ acknowledge the financial support from $\mathrm{CNU}$.

Supplementary Materials. Supplementary data associated with this article can be obtained free of charge from the Cambridge Crystallograplic Data Centre (CCDC 650333).

\section{References}

1. (a) Smela. E.: Inganas. O: Lundstrom. I. Science 1995. 268. 1735 (b) Shotheim. T. A.: Elsenbaumer. R. L:: Reynolds. J. R. Hamdbook of Conducting Polmmens. 2nd ed: Dekker: New York. 1998. (c) Al-Yusufy, F. A.: Bruckenstein. S.: Schlindwein. W. S. J. Solid State Electrochem. 2007. 11. 1263. (d) Pu. S.; Liu. G.; Shen. L.: Xu, J. Org. Lett. 2007, 9. 2139 . (e) Li, G: Wang. Y: Xu, H. Sentsors 2007. 7. 239. (e) varis. S.: Ak. M.: Aklumedor. I. M: Tanyeli. C.: Toppare. L. J. Electroanah Chent 2007. 605.8.

2. Diaz. A. F.: Kanazawa. K. K. J. Chent. Soc. Chem. Conmmm. 1979. 635

3. Nazzal, A.: Street, G. B. d. Chem. Soc. Chem. Commun, 1983, 84.

4. Kim. I. T. Elsenbaumer, R. L. Hacromolecules 2000, 33.6407.

5. Kang. J.Gi: Kim. T.-T.: Park. C.: Lee. S. W: Kim. I. T. bull. Korean Chem. Soc. 2004. 25. 704.

6. Goldoni. F.: Antolini. L.: Pourtois. G: Schenting. A. P. H. J.: Janssen, R. A. J.; Lazzaroni. R.: Bredas. J.-L: Meijer, E. W. Eur J. Inor: Chem. 2001. 821 .

7. Groot. B. de Hanan, G. S.: Loeb, S. J. Horg. Chem. 1991, 30, 4644

8. Gladiali. S.: Fabbri. D.: Kollar. L.: Claver. C.: Ruiz. N.: AlvarezLarena. A. Ent J. Inotg. Chem. 1998. 113.

9. Adrio. L.: Alberdi. G: Amoedo. A.: Lata. D.: Fernandez. A.: Martinez, J. Pereira, M. T.: Vila, J. M. Z. Anomg Alleg. Chen. 2005. 631, 2197.

10. Park, Y.-A.: Na. Y. Back. D.-J. Bull Korean Chem. Soc. 2006, 27. 2023.

11. Yunı. S.-S.: Kim. J.-K.: Jung. J.-S.: Park. C.: Kan1g. J.-G.: Smyth. D. R.: Tiekink. R. T. Crnstal Gowh \& Design 2006. 6.899.

12. Kang. J.-G:; Kim, T.-J:: Park. C.: Lee, S. W.: Kim, I. T. Bull. Korean Chem. Soc. 2004. 25,704.

13. Gatssian 03. Revision C.02: Gaussian. Inc.: Wallingford. C. 2004 